\title{
PENGARUH BUDAYA ORGANISASI DAN MOTIVASI TERHADAP KEPUASAN KERJA SMP/SMK IPTEK DI TANGSEL
}

\author{
Jonathan dan Kurniati W. Andani \\ Program Studi Manajemen/Akuntansi Fakultas Ekonomi Universitas Tarumanagara, Jakarta \\ Jonathan.115150210@stu.untar.ac.id
}

\begin{abstract}
The purpose of this research is to examine whether:organizational culture can impact job satisfaction SMK/SMP IPTEK Tangsel and motication can implact job satisfaction SMK/SMP IPTEK Tangsel. Sample was selected using total sampling method method amounted to 50 respondents. The result of this study show organizational culture and motivation has significant effect to impact job satisfaction. This research can be used as input for SMK/SMP IPTEK Tangsel to increase job satisfaction.
\end{abstract}

Keywords : Organizational Culture, motivation, job satisfaction

Abstrak: Tujuan dari penelitian ini adalah untuk penguji : pengaruh budaya organisasi terhadap kepuasan kerja SMK/SMP IPTEK Tangsel dan pengaruh pengaruh motivasi terhadap kepuasan kerja SMK/SMP IPTEK Tangsel. Sampel yang digunakan dalam penelitian ini adalah guru dan staff SMK/SMP IPTEK Tangsel dengan metode total sampling dengan jumlah populasi sebanyak 50 responden.. Penelitian ini dapat digunakan sebagai masukan bagi SMK/SMPIPTEK Tangsel untuk mengukur kepuasan kerja.

Kata Kunci: Budaya Organisasi, Motivasi, Kepuasan Kerja

\section{LATAR BELAKANG}

Guru merupakan salah satu komponen terpenting dalam suatu organisasi di bidang pendidikan. Figur guru menjadi peran utama dalam dunia pendidikan untuk menentukan keberhasilan peserta didik dan keberlangsungan proses belajar mengajar. Guru bukan satusatunya faktor penting dalam menentukan berhasil atau tidaknya pendidikan. Ada faktor penting yaitu staff pembantu kegiatan belajar mengajar yaitu tata usaha yang bertugas untuk mengurus administrasi siswa dan guru dalam sistem pendidikan, kepala sekolah yang bertugas menyusun perencanaan sekolah serta program belajar mengajar, dan perangkat lainnya pendukung sistem pendidikan.

Sumber daya manusia menjadi salah satu faktor penentu kesuksesan sistem pendidikan. Sumber daya manusia yang baik akan menentukan lulusan yang baik juga karena kegiatan belajar mengajar berlangsung dengan baik. Oleh karena itu organisasi dalam dunia pendidikan harus memperhatikan kepuasan kinerja karyawan agar seluruh anggota organisasi dapat melakukan tanggung jawabnya dengan sebaik mungkin.

Motivasi juga menjadi faktor penting dalam mendorong kepuasan kerja, menurut Wibowo (2016) motivasi adalah keinginan untuk bertindak atau melakukan sesuatu untuk mencapai tujuan. Mengacu pada uraian diatas maka kepuatasan kerja menjadi acuan utama bagi ketua organisasi dalam membina organisasi dan memajukan organisasi. Untuk itu, peneliti ingin melakukan penelitian di Yayasan SMK dan SMP IPTEK Tangsel karena terdapat masalah penurunan motivasi mengajar sejak kegiatan belajar mengajar dilakukan secara online. Peneliti 
melakukan penelitian di Yayasan SMK dan SMP IPTEK Tangsel untuk mempelajari mengenai budaya organisasi dan motivasi terhadap kepuasan kerja karyawan.

\section{KAJIAN TEORI}

\section{Budaya Organisasi}

Budaya organisasi adalah kumpulan nilai dan keyakinan dalam sebuah organisasi. Hal ini dapat mempengaruhi perilaku dan tindakan individu dalam suatu organisasi. Robbins dan Coulter (2010), Menurut Schein (1992), \& Mgbere (2010).

\section{Motivasi}

Motivasi adalah suatu proses yang mendorong seorang individu untuk mencapai tujuan. Elemen yang terdapat pada motivasi berupa arahan yang tepat, pembangkit semangat, menjaga perilaku invidu dalam mencapai tujuan, dan bersifat terus-menerus. Robbins (2003), Cerasoli et, al (2014), \& Greenberg \& Baron (2003).

\section{Kepuasan Kerja}

kepuasan kerja adalah suatu sikap seorang individu dalam pekerjaannya, sikap ini terbagi menjadi dua yaitu puas dan tidak puas. Kepuasan atau ketidakpuasan bersifat personal yang bergantung pada seorang individu mempersepsikan antara keinginan dengan hasil yang didapat. Robbins (2013), Gunawan, R. (2016), \& Kreitner \& Kinicki (2001).

\section{Kaitan Antar Variabel Budaya Organisasi Tehadap Kepuasan Kerja}

Surya, M., I. \& Widjaja O., H. (2020) melakukan penelitian mengenai budaya organiasi dan motivasi terhadap kepuasan kerja di Jakarta. Menggunakan 50 responden kuesioner yang disebarkan melalui kuesioner online dengan teknik analisis PLS-SEM.

Pawirowumarto, dkk. (2016) melakukan penelitian mengenai budaya organisasi terhadap kepuasan kerja hasilnya positif dan signifikan, bahwa budaya organisasi dapat mempengaruhi kepuasan kerja secara langsung. Penelitian dilakukan di Indonesia dengan total populasi sebanyak 642 responden dan sampel yang diambil dari populasi yaitu sebanyak 179 responden dengan menggunakan teknik analis PLS-SEM.

Tran, Q., H. (2019) menyatakan budaya organisasi memiliki hubungan yang signifikan terhadap kepuasan karyawan. Individu yang dapat diterima oleh sebuah organisasi dan memiliki tujuan yang sama dapat membangkitkan semangat dan mendapatkan kepuasan kerja. Penelitian dilakukan di Vietman menggunakan 294 responden dengan metode analisis SPSS.

\section{Kaitan Antar Variabel Motivasi Terhadap Kepuasan Karyawan}

Reizer, dkk. (2018) melakukan penelitian mengenai prediksi motivasi karyawan terhdap kepuasan kerja hasilnya bahwa motivasi dapat meningkatkan kepuasan kerja karyawan. Penelitian dilakukan di Israel dengan menggunakan 116 responden, penelitian dilakukan menggunakan metode AMOS.

Omar, dkk. (2021) melakukan penelitian mengenai motivasi dapat berpengaruh terhadap kepuasan kerja. Hasilnya adalah positif dan signifikan bahwa motivasi adalah sebagai faktor penting menciptakan kepuasan kerja karena seseorang yang ingin mencapai kepuaasn kerja maka akan memiliki motivasi untuk mencapai tujuan tersebut. Penelitian menggunakan 169 sampel yang berasal dari karyawan dibidang perhotelan dan penelitian menggunakan metode PLS-SEM. Nursyirwan, V., I (2019) melakukan penelitian mengenai pengaruh motivasi terhadap kepuasan kerja. Hasilnya adalah motivasi berpengaruh postif terhadap kepuasan kerja. Penelitian menggunakan 80 sampel karyawan Bank X di Jakarta dan menggunakan bantuan metode SPSS. 


\section{Kerangka Pemikiran}

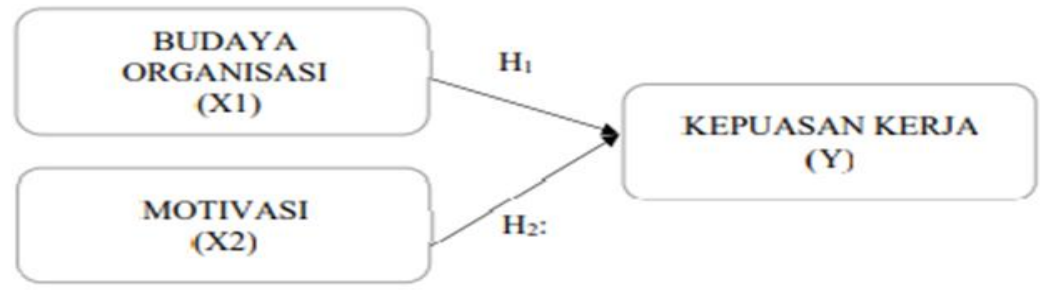

\section{Hipotesis}

H1: Budaya organisasi berpengaruh signifikan terhadap kepuasan kerja

H2: Motivasi berpengaruh signifikan terhadap kepuasan kerja.

\section{Metodologi}

Comrey (1973) dalam Aritonang (2007) menjelaskan bahwa sampel ideal yang dapat digunakan dalam penelitian adalah sebanyak 100-200 sampel. Karena jumlah populasi kurang dari 100 orang maka teknik pengumpulan dengan cara total sampling adalah dimana jumlah sampel yang akan diuji sama banyaknya dengan jumlah populasi yang ada yaitu sebanyak 50 responden. Penelitian ini adalah penelitian asosiatif kausalistik yang menguji pengaruh budaya organisasi terhadap kepuasan kerja dan pengaruh motivasi terhadap kepuasan kerja.

Pengukuran variabel - variabel dalam penelitian ini mengacu pada penelitian sebelumnya antara lain sebagai berikut :

\begin{tabular}{|l|c|l|}
\hline \multicolumn{1}{|c|}{ Variabel } & Indikator & \multicolumn{1}{c|}{ Acuan } \\
\hline Budaya Organisasi & 5 item & Julianto \& Hendriani (2014) \\
\hline Motivasi & 5 item & Hasibuan (2012) \\
\hline Kepuasan Kerja & 5 item & Hasibuan (2012) \\
\hline
\end{tabular}

\section{Hasil Analisis Data}

Hasil analisis pada penelitian ini menunjukkan bahwa setiap variabel memiliki nilai average variance extracted lebih dari 0,50 (>0,5) maka pada validitas konvergen nilai penelitian ini dianggap valid. Selanjutnya analisis reliabilitas untuk menguji apakah data dapat dianggap reliabel atau tidak dengan cara mencari nilai composite reliability tidak boleh kurang dari 0,70 $(>0,7)$. Pada penelitian ini setiap variabel memperoleh nilai composite reliability lebih dati 0,70 $(>0,7)$ maka penelitian ini sudah memenuhi syarat. Maka masing - masing indikator yang digunakan dianggap sudah mewakili setiap variabel dianggap valid dan reliabel.

Hasil Uji Average Variance Extracted (AVE)

\begin{tabular}{|l|l|}
\hline Variabel & Average Variance Extracted \\
\hline Budaya Organisasi & 0,813 \\
\hline Motivasi & 0,754 \\
\hline Kepuasan Kerja & 0,749 \\
\hline
\end{tabular}




\section{Hasil Uji Composite Reliability}

\begin{tabular}{|l|l|}
\hline \multicolumn{1}{|c|}{ Variabel } & \multicolumn{1}{|c|}{ Composite Reliability } \\
\hline Budaya Organisasi & 0,956 \\
\hline Motivasi & 0,939 \\
\hline Kepuasan Kerja & 0,937 \\
\hline
\end{tabular}

Hasil Uji Cronbach Alpha

\begin{tabular}{|l|l|}
\hline Variabel & Cronbach Alpha \\
\hline Budaya Organisasi & 0,942 \\
\hline Motivasi & 0,918 \\
\hline Kepuasan Kerja & 0,916 \\
\hline
\end{tabular}

Hasil Uji Loading Factor

\begin{tabular}{|l|l|l|l|l|l|}
\hline & \multicolumn{1}{|c|}{$\begin{array}{c}\text { Budaya } \\
\text { Organisasi }\end{array}$} & $\begin{array}{c}\text { Kepuasan } \\
\text { Kerja }\end{array}$ & \multicolumn{1}{|c|}{ Motivasi } \\
\hline BO1 & 0,889 & KK1 & 0,893 & M1 & 0,855 \\
\hline BO2 & 0,956 & KK2 & 0,905 & M2 & 0,831 \\
\hline BO3 & 0,846 & KK3 & 0,802 & M3 & 0,905 \\
\hline BO4 & 0,867 & KK4 & 0,861 & M4 & 0,854 \\
\hline BO5 & 0,944 & KK5 & 0,851 & M5 & 0,896 \\
\hline
\end{tabular}

Hasil Uji R-square $\left(\mathrm{R}^{2}\right)$

\begin{tabular}{|l|l|l|}
\hline & \multicolumn{1}{|c|}{ R-Square } & R-Square Adjusted \\
\hline Kepuasan Kerja & 0,905 & 0,901 \\
\hline
\end{tabular}

Hasil Uji Q-square $\left(Q^{2}\right)$

\begin{tabular}{|l|l|}
\hline & \multicolumn{1}{c|}{ Q-square } \\
\hline Kepuasan Kerja & 0,631 \\
\hline
\end{tabular}


Pengujian Effect Size $\left(\mathbf{F}^{2}\right)$

\begin{tabular}{|c|c|c|c|}
\hline & $\begin{array}{c}\text { Budaya } \\
\text { Organisasi }\end{array}$ & $\begin{array}{c}\text { Kepuasan } \\
\text { Kerja }\end{array}$ & Motivasi \\
\hline Budaya Organisasi & & 0,228 & \\
\hline Kepuasan Kerja & & & \\
\hline Motivasi & & 0,256 & \\
\hline
\end{tabular}

\section{DISKUSI}

\section{Hasil Pengujian Hipotesis}

\begin{tabular}{|c|l|c|}
\hline Hipotesis & \multicolumn{1}{|c|}{ Pernyataan Hipotesis } & Hasil \\
\hline H1 & $\begin{array}{l}\text { Budaya organisasi berpengaruh positif } \\
\text { dan signifikan terhadap kepuasan kerja }\end{array}$ & Tidak Ditolak \\
\hline H2 & $\begin{array}{l}\text { Motivasi berpengaruh positif dan } \\
\text { signifikan terhadap kepuasan kerja }\end{array}$ & Tidak Ditolak \\
\hline
\end{tabular}

Berdasarkan pada tabel kesimpula hasil variabel independen budaya organisasi dan motivasi dapat mempengaruhi secara signifikan dan positif terhadap kepuasan kerja SMP/SMK IPTEK di Tangsel, maka seluruh hipotesis yang peneliti buat tidak ditolak.

\section{PENUTUP}

Penelitian ini dilakukan untuk menguji pengaruh variabel independen terhdap variabel dependen. Budaya organisasi (X1) dan motivasi (X2) sebagai variabel indepnden terhadap variabel dependen yaitu kepuasan kerja (Y1). Penelitian ini dilakukan di SMP/SMK IPTEK Tangsel menggunakan kuesioner google-form menggunakan 50 sampel. Aplikasi yang digunakan untuk menganalisis hasil penelitian adalah SmartPLS versi 3 for windows.

Berdasarkan hasil penelitian yang telah dilakukan maka dapat disimpulkan bahwa budaya organisasi berpengaruh postif dan signifikan terhadap kepuasan kerja karyawan SMP/SMK IPTEK Tangsel dan otivasi berpengaruh postif dan signifikan terhadap kepuasan kerja karyawan SMP/SMK IPTEK Tangsel.

Saran SMP/SMP IPTEK di Tangsel dapat konsisten dalam penetuan budaya organisasi sesuai dengan aturan perusahaan yang sudah ada. Yang bertujuan untuk mencapai visi perusahaan dimasa yang akan datang.

\section{DAFTAR PUSTAKA}

Abdillah, W. \& Jogiyanto. (2015). Partial Least Square (PLS), Alternatif Structural Equation Modeling (SEM) dalam Penelitian Bisnis. Yogyakarta: Penerbit Andi. 
Arikunto, S. (2016). Prosedur Penelitian. Jakarta : Rineka Cipta

Aritonang, L R. (2007). Riset Pemasaran Teori : Teori dan Praktek. Jakarta : Galia Indonesia.

Cerasoli, C.P., Nicklin, J.M. \& Ford, M.T. (2014), "Intrinsic motivation and extrinsic incentives jointly predict performance: a 40-year meta-analysis", Psychological Bulletin Journal, Vol. 140 No. 4.

Ehrhart, M.G., Schneider, B. and Macey, W.H. (2013), Organizational Climate and Culture: An Introduction to Theory, Research, and Practice, Routledge, London.

Fry, L.W. (2003), “Toward a theory of spiritual leadership", The Leadership Quarterly Journal, Vol. 14 No. 6.

Geenberg, Jerald dan Robert A. Baron. (2003), Behavior in Organization, New Jersey: Prentice Hall

Ghozali. I \& Latan. H. 2015. Partial Least Squares Konsep, Teknik dan Aplikasi Menggunakan Progam SmartPLS 3.0 Edisi 2 Untuk Penelitian Empiris. Semarang: Badan Penerbit Universitas Diponegoro

Gibson, James L. John M Ivancevich dan James H. Donnelly, Jr. (2000). Organizations. Boston: Mcgraw-Hill Companies, Inc.

Gunawan, Rahmat (2016) The effect of work environment, leadership style, and organizational culture towards job satisfaction and its implication towards employee performance in Parador Hotels and Resorts, Indonesia, International Journal of Law and Management, Vol 56, No. 4.

Hair, F. J., Black, C. W., Babin, J. B., \& Anderson, E. R. (2014). Multivariate Data Analysis (MVDA A Global Perspective). Seventh Edition. Pearsons.

Harwiki, W., (2016) "The impact of servant leadership on organization culture, organizational commitment, organizational citiznship bhavior, and employee performance in woman cooperatives" Procedia Social and Behavioral Sciences Journal, Vol. 219.

Hasibuan, Malayu S.P. (2016), Manajemen Sumber Daya Manusia, Edisi Revisi, Jakarta: PT Bumi Aksara

Hofstede, G. (2011), "Dimensionalising cultures: the Hofstede model in context", Journal of Online Readings in Psychology and Culture, Vol. 2 No. 1.

Hogan, S.J. and Coote, L.V. (2014), "Organizational culture, innovation, and performance: a test of schein's model”, Journal of Business Research, Vol. 67 No. 8.

Kast, Fremont E dan James E Rosenzweig. (2007). Organisasi \& Manajemen. Jakarta: PT Bumi Aksara.

Kreitner, Robert dan Angelo Kinicki. (2001). Organizational Behavior. New York: McgrawHill Companies, Inc

Makmuri, Muchlas. (2005). Perilaku Organisasi. Yogyakarta: Gadjah Mada University Press.

Maryam, A., Bader, A., \& Faisal, N.M. (2016) Influence of organizational culture and leadership style on employee satisfaction, commitment and motivation in the educational sector in Qatar, Journal of Business, Vol. 12(2).

Mgbere, O. (2009), "Exploring the relationship between organizational culture, leadership styles and corporate performance: an overview", Journal of Strategic Management Education, Vol. 5(3). 
Omar, S. M., Idrus, M. I., \& Jaman, A. N. (2021) The Influence of Job Motivation on Job Satisfaction: A Case Study of Polytechnic Academic Staff, Malaysian Journal of Social Sciences and Humanities, Vol. 6(2).

Pawirosumarto, S., Sarjana, K., P., \& Gunawan, R. (2016) The effect of work environment, leadership style, and organizational culture towards job satisfaction and its implication towards employee performance in Parador Hotels and Resorts, Indonesia, International Journal of Law and Management, Vol. 59(6).

Raizer, A., Ilan, Y. B., \& Sheaffer, Z. (2018) Employee motivation, emotions, and performance: a longitudinal diary study, Journal of Managerial Psychology, Vol. 34(6).

Robbins, S.P. (1998). Organizational Behavior: Concepts, Controversies, and Applications, Seventh Edition. Jakarta: Englewood Cliffs dan PT. Prenhallindo , (2003) Organizational Behavior. New Jersey: Prentice Hall.

Robbins, S.P. \& Mary Coulter. (2010). Manajemen. Edisi Kesepuluh. Jakarta: PT. Indeks.

Robbins, S.P. (2013) Organizational Behaviour edition 15, Upper Saddle River, Nj : Pearson

Schein, E.H. (1992), Organizational Culture and Leadership, Jossey-Bass Publishers, San Francisco, CA.

Surya, M., I. \& Widjaja O., H. (2020) Pengaruh Budaya Organisasi dan Motivasi Kerja terhadap Kepuasan Kerja di PT. Planet Selancar Mandiri di Jakarta, Jurnal Manajerial dan Kewirausahaan, Vol 2(4).

Sekaran, U. \& Bougie, R. (2013). Research Methods for Business (Vol. 6th Ed.). Italy: Printer Trento Srl.

Sugiyono. (2016). Metode Penelitian Kuantitatif, Kualitatif, dan R\&D. Bandung: Alfabet

Tran, Q.H.N. (2019) Organisational culture, leadership behaviour and job satisfaction in the Vietnam context, International Journal of Organizational Analysis, Vol. 29(1).

Wibowo. (2016). Manajemen Kinerja Edisi Kelima. Jakarta: PT Grafindo Persada.

Yakup, Yakup. (2017) Pengaruh Keterlibatan Kerja, Budaya Organisasi dan Motivasi Kerja Terhadap Kepuasan Kerja Pegawai. Jurnsl Perisai, Vol 1 (3) 